\title{
Pd/Au Based Catalyst Immobilization in Polymeric Nanofibrous Membranes via Electrospinning for the Selective Oxidation of 5-Hydroxymethylfurfural
}

\author{
Danilo Bonincontro $\left.{ }^{1}{ }^{(}\right)$, Francesco Fraschetti ${ }^{1}$, Claire Squarzoni ${ }^{1}$, Laura Mazzocchetti ${ }^{1,2}{ }^{\circledR}$,

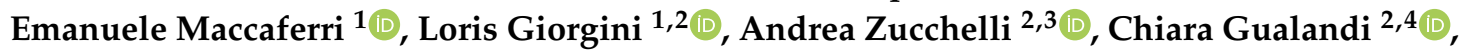 \\ Maria Letizia Focarete ${ }^{4}$ (D) and Stefania Albonetti ${ }^{1, *(D)}$ \\ 1 Department of Industrial Chemistry Toso Montanari, University of Bologna, Viale Risorgimento, 4, \\ 40136 Bologna, Italy; danilo.bonincontro2@unibo.it (D.B.); fr.fraschetti@yahoo.it or \\ francesco.fraschetti@studio.unibo.it (F.F.); claire.squarzoni@gmail.com or \\ claire.squarzoni@etu.chimieparistech.psl.eu (C.S.); laura.mazzocchetti@unibo.it (L.M.); \\ emanuele.maccaferri3@unibo.it (E.M.); loris.giorgini@unibo.it (L.G.) \\ 2 Interdepartmental Center for Industrial Research on Advanced Applications in Mechanical Engineering and \\ Materials Technology, CIRI-MAM, University of Bologna, Viale Risorgimento, 2, 40136 Bologna, Italy; \\ a.zucchelli@unibo.it (A.Z.); c.gualandi@unibo.it (C.G.) \\ 3 Department of Industrial Engineering, University of Bologna, Viale Risorgimento, 2, 40136 Bologna, Italy \\ 4 Department of Chemistry Giacomo Ciamician and INSTM UdR of Bologna, University of Bologna, \\ Via Selmi, 2, 40126 Bologna, Italy; marialetizia.focarete@unibo.it \\ * Correspondence: stefania.albonetti@unibo.it
}

Received: 6 December 2019; Accepted: 30 December 2019; Published: 1 January 2020

\begin{abstract}
Innovative nanofibrous membranes based on $\mathrm{Pd} / \mathrm{Au}$ catalysts immobilized via electrospinning onto different polymers were engineered and tested in the selective oxidation of 5-(hydroxymethyl)furfural in an aqueous phase. The type of polymer and the method used to insert the active phases in the membrane were demonstrated to have a significant effect on catalytic performance. The hydrophilicity and the glass transition temperature of the polymeric component are key factors for producing active and selective materials. Nylon-based membranes loaded with unsupported metal nanoparticles were demonstrated to be more efficient than polyacrylonitrile-based membranes, displaying good stability and leading to high yield in 2,5-furandicarboxylic acid. These results underline the promising potential of large-scale applications of electrospinning for the preparation of catalytic nanofibrous membranes to be used in processes for the conversion of renewable molecules.
\end{abstract}

Keywords: polymeric catalytic membranes; electrospinning; HMF oxidation

\section{Introduction}

Monomer and polymer production from renewable feedstocks has become a relevant research target with the aim of providing more environmental friendly solutions to the actual fossil-based market [1-6]. In this framework, 5-(hydroxymethyl)furfural (HMF) is recognized as an ideal platform molecule to develop different green products, since it can be obtained via acid-catalyzed dehydration of biomass-derived sugars [7-9], and, in turn, it can be converted into a wide range of different high added value chemicals [10-13]. Among the HMF products, 2,5-furandicarboxylic acid (FDCA, Scheme 1) has been identified as one of the most interesting [14], since it can be considered as the bioderived counterpart of terephthalic acid for the production of polyesters [15], such as polyethylene 2,5-furandicarboxylate 
(PEF), being the latter the potential candidate to replace polyethylene terephthalate (PET) in bottle production [16,17].

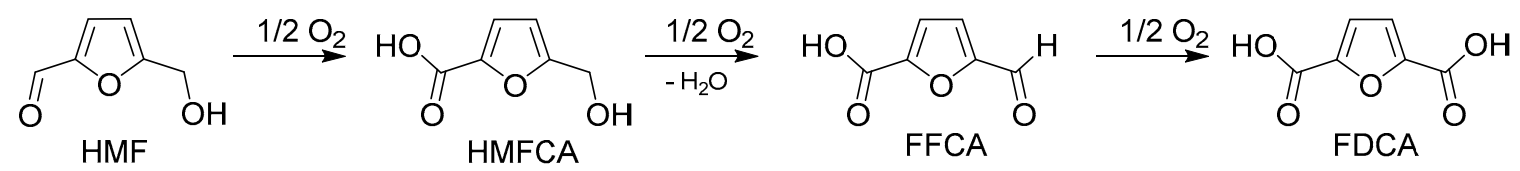

Scheme 1. 5-(hydroxymethyl)furfural selective oxidation to 2,5-furandicarboxylic acid.

First attempts to industrially convert HMF to FDCA relied on the technologies developed for terephthalic acid production [18]. However, the use of corrosive solvent, homogeneous catalysts and harsh operative conditions forced the investigation of other catalytic systems in order to overcome such constraints. In this regard, precious metal nanoparticles showed their high potential, Au-based systems being the most investigated [19-21]. In the definition of the properties of such catalytic systems, several parameters seem to be fundamental such as: nanoparticle composition and dimension, support/nanoparticle interaction and support surface textural properties. The fine tuning of such parameters can lead to very active systems. For instance, by alloying Au with another metal (such as $\mathrm{Cu}[22,23]$ or Pd $[24,25]$ ) it is possible to effectively enhance FDCA yield, or by choosing suitable supports catalytic activity can be positively affected [26] and/or base addition can be avoided [27-29]. Besides the textural properties that have been shown to play a prominent role, pore dimension and acid/base sites can be considered of crucial importance [30]. Thus, it is evident that the design and synthesis of materials that possess suitable features can lead to optimal catalytic activity.

As far as the setups employed to carry out this reaction, batch ones are the most studied. However, the economical sustainability of this kind of approach is still a concern [31]. Thus, to address this issue, efforts must be devoted to process intensification, for instance by evaluating the possibility of developing inexpensive catalytic systems to perform this reaction continuously [32,33], and, in this frame, recent reports have highlighted the interest of both industrial $[34,35]$ and academic research $[36,37]$. In this context, the use of catalytic membranes is known to provide several advantages, making them efficient tools for applications in several industrial fields [38]. In the case of HMF oxidation, considering that the reaction is carried out under mild operative conditions $\left(70-120^{\circ} \mathrm{C}\right)$, it is possible that the use of composite polymeric membranes might be advantageous. Along with all the advantages related to the more traditional inorganic membranes, these materials are characterized by low production costs, ease of handling and tunability of their properties [39].

Electrospinning provides a convenient approach for the preparation and scale-up of membranes made of continuous sub-micrometric fibers characterized by large surface area and porosity $[40,41]$. This could represent an interesting strategy for the production of catalytic membranes, which can be used in processes for biomass valorization. Briefly, this technology uses electrostatic forces to uniaxially stretch a viscoelastic jet derived from a polymer solution to produce fibers having diameters ranging from a few tenths of nanometers to a few micrometers, collected as nonwovens with mesh porosity typically higher than $80 \%$ and pore diameters that can vary from a few to tens of micrometers.

Electrospun membranes are currently being investigated as materials for the support of heterogeneous catalysts by following different technological approaches, the main one being the production of ceramic fibers that support metal nanoparticles [40]. In this case, a polymer solution containing ceramic precursors and metal salts is electrospun and subsequently heat treated under inert gas to eliminate the organic components and reduce the metal precursor to metal nanoparticles [42-45]. This approach permits the achievement of high catalytic performances by exploiting the high surface area of the fibers but suffers from the high fragility of the completely inorganic nonwoven. Conversely, by keeping unaltered the organic polymeric component, membrane flexibility and handling can be massively improved. Following this approach, polymeric electrospun nanofibers have been decorated at the surface with metal nanoparticles (NPs) $[46,47]$ in an elegant and effective way that exploits polymer bulk properties and maximizes the catalytic effect. However, NP immobilization at a fiber 
surface requires a further step in the production process that is time consuming and hardly applicable at the industrial level. Moreover, leaching of metal NPs from a fiber surface cannot be excluded.

In this work, electrospinning is used in a simple and scalable single-step approach for the production of electrospun polymer-inorganic catalytic membranes, potentially suitable for batch and continuous processes. Membranes were manufactured by incorporating preformed $\mathrm{Au}$ and $\mathrm{Au} / \mathrm{Pd}$ $\mathrm{NPs}(\mathrm{Au} / \mathrm{Pd}$ molar ratio 6, which was demonstrated to promote the highest catalytic activity in this reaction [24]) and $\mathrm{TiO}_{2}$ in the starting polymeric solutions. To optimize catalytic activity and stability, two different polymers have been tested-i.e., polyacrylonitrile (PAN) and Nylon 6,6 (NYL)—loaded with $\mathrm{Au}$ and alloyed $\mathrm{Au} / \mathrm{Pd} \mathrm{NPs}$, either directly supported on $\mathrm{TiO}_{2}$ or simply combined with $\mathrm{TiO}_{2}$ during electrospinning. The catalytic activity of catalysts contained in different electrospun membranes towards HMF oxidation to FDCA has been investigated with the goal of highlighting the effect of polymer/inorganic combination on membrane performance. The materials were evaluated in batch experiments to assess the viability for use of electrospun polymer-based catalytic membranes in the conversion of renewable molecules in water.

\section{Materials and Methods}

\subsection{Materials}

Polyacrylonitrile (PAN, $\mathrm{M}_{\mathrm{w}}=1.5 \times 10^{5} \mathrm{~g} / \mathrm{mol}$ ) was purchased from Sigma-Aldrich (St. Louis, MO, USA). Nylon 6,6 (NYL, Zytel ${ }^{\circledR}$ E53 NC010) was kindly provided by DuPont (Wilmington, DE, USA). Dimethylformamide (DMF), formic acid (FA) and chloroform (CLF), $\mathrm{HAuCl}_{4}, \mathrm{PdCl}_{2}$, glucose, $\mathrm{NaOH}$ and polyvinylpyrrolidone (PVP) were purchased from Sigma Aldrich and were used without further purification. HMF (purity $>99 \%$ ) was purchased from AVABiochem (Muttenz, Switzerland) and used without any purification.

\subsection{Nanoparticle Synthesis}

Au-based nanoparticle synthesis was performed as previously reported [24]. As a general approach, a suitable amount of the metal precursors $\left(\mathrm{HAuCl}_{4}\right.$ and $\left.\mathrm{PdCl}_{2}\right)$ were dissolved in water. Once dissolved, glucose, $\mathrm{NaOH}$ and the stabilizing agent (PVP) were added to the solution and allowed to react for $2.5 \mathrm{~min}$ at $95^{\circ} \mathrm{C}$ under solvent reflux. Then, the resulting nanoparticle suspension was concentrated using $50 \mathrm{kDa}$ Amicon Ultra filters (Millipore, Burlington, MO, USA) to eliminate excess water. The concentrated suspension was impregnated onto $\mathrm{TiO}_{2}$ in order to achieve a metal loading (pristine $\mathrm{Au}$ or $\mathrm{Au}+\mathrm{Pd}$ with 6/1 metal ratio) of $1.5 \mathrm{wt} . \%$. After the impregnation, solvent was evaporated by thermal treatment at $120^{\circ} \mathrm{C}$. Alternatively, another batch of the $\mathrm{Au}_{6} \mathrm{Pd}_{1} \mathrm{NPs}$ colloidal suspension was washed with formic acid in two subsequent filtrations to replace water.

\subsection{Production of Electrospun Membranes}

Electrospun non-woven mats with random arrangement of fibers were fabricated using an electrospinning machine (Spinbow s.r.l, Bologna, Italy). Briefly, the electrospinning apparatus was composed of a high voltage power supply, a syringe pump and a glass syringe containing the polymer solution connected to a stainless-steel blunt-ended needle through a polytetrafluoroethylene tube. A grounded plate collector was vertically positioned below the tip of the needle. Electrospinning was performed at room temperature (RT) and relative humidity $40 \%-50 \%$.

PAN and nylon based membranes were prepared using a stainless-steel blunt needle (inner diameter $=0.84 \mathrm{~mm})$ and collected on a plate collector $\left(25 \times 25 \mathrm{~cm}^{2}\right)$. First membranes containing plain $\mathrm{TiO}_{2}$ and $\mathrm{TiO}_{2}$ supported $\mathrm{Au}_{6} \mathrm{Pd}_{1}$ nanoparticles, together with a reference polymeric membrane, were prepared. Then, membranes containing unsupported $\mathrm{Au}_{6} \mathrm{Pd}_{1}$ nanoparticles and $\mathrm{TiO}_{2}$ independently added and just $\mathrm{Au}_{6} \mathrm{Pd}_{1}$ nanoparticles were also produced. The residual solvent in the membranes was removed by thermal treatment at $80^{\circ} \mathrm{C}$ for $3 \mathrm{~h}$ in static air. The mass loss due to the drying was around $1 \%-3 \%$ for all the membranes. 
The detailed description of solution preparation and electrospinning conditions for all the produced samples are reported in the Supporting Information section (Tables S1-S3, Figures S1 and S2).

\subsection{Characterization Methods}

X-ray diffraction (XRD) measurements were carried out at room temperature with a Bragg/Brentano diffractometer (X'pertPro PANalytical - Malvern Panalytical Ltd, Malvern, UK) equipped with a fast $\mathrm{X}^{\prime}$ Celerator detector, using a $\mathrm{Cu}$ anode as the $\mathrm{X}$-ray source $\left(\mathrm{K}_{\alpha}=1.5418 \AA\right)$. For all samples, diffractograms were recorded in the range $35-44^{\circ} 2 \theta$, counting for 1000 s every $0.1^{\circ} 2 \theta$ step. Crystallite size values were calculated using the Scherrer equation from the full width at half maximum intensity measurements.

Scanning electron microscopy (SEM) observations were carried out by using a Leica Cambridge Stereoscan 360 scanning electron microscope (Leica, Cambridge, UK) at an accelerating voltage of 20 $\mathrm{kV}$, on samples sputter-coated with gold. The distribution of fiber diameters was determined through the measurement of about 150 fibers and the results were given as the average diameter \pm standard deviation (SD).

Transmission electron microscopy (TEM) observations were carried out by using a FEI Tecnai F20 microscope (Thermo Fisher Scientific, Waltham, MA, USA) equipped with a Schottky emitter and operating at $200 \mathrm{KeV}$. The fibers were electrospun directly on a TEM copper grid (100 mesh).

Differential scanning calorimetry (DSC) measurements were carried out using a TA Instruments Q100 DSC (Thermal Analysis Instruments, New Castle, PA, USA) equipped with the liquid nitrogen cooling system accessory. DSC scans of electrospun membranes were performed in helium atmosphere at a heating rate of $20^{\circ} \mathrm{C} / \mathrm{min}$. The glass transition temperature $\left(\mathrm{T}_{\mathrm{g}}\right)$ was taken at half-height of the glass transition heat capacity step, while the melting temperature $\left(\mathrm{T}_{\mathrm{m}}\right)$ was taken at the peak maximum of the melting endotherm.

Thermogravimetric analyses (TGA) were carried out using a TGA Q500 thermogravimetric analyzer (TA Instruments, New Castle, DE, USA). Analyses were performed from RT to $700^{\circ} \mathrm{C}$, at a heating rate of $10^{\circ} \mathrm{C} / \mathrm{min}$, under air flow.

The BET specific surface area of each catalyst was determined by $\mathrm{N}_{2}$ absorption-desorption at liquid $\mathrm{N}_{2}$ temperature, using a Sorpty 1750 Fison instrument (Micromeritics Instruments Corporation, Norcross, GA, USA). Prior $\mathrm{N}_{2}$ absorption samples were outgassed at $50^{\circ} \mathrm{C}$.

\subsection{Catalytic Tests}

A lab scale autoclave reactor (100 mL capacity from Parr) (Parr Instrument Company, Moline, IL 61265-1770, USA), equipped with a mechanical stirrer (0-600 rpm) and sensors for temperature and pressure measurement, was used to carry out the catalytic tests. An aqueous solution of HMF (25 $\mathrm{mL}, 18 \mathrm{mM})$ and $\mathrm{NaOH}(\mathrm{NaOH} / \mathrm{HMF}$ molar ratio $=2)$ and the membrane previously cut into small squared pieces of $1 \mathrm{~cm}^{2}(\mathrm{HMF} /$ total metal molar ratio $=100)$ were loaded in the reactor. To perform the reactivity tests, the autoclave reactor was purged three times with $\mathrm{O}_{2}(2 \mathrm{bar})$ and then pressurized at 10 bar. The temperature was increased to the set point and the reaction mixture was stirred at $600 \mathrm{rpm}$ for the whole duration of the experiment ( $4 \mathrm{~h}$ if not stated differently). As reaction initial time (time zero) for the reaction was considered when the set point temperature was reached (after $10 \mathrm{~min}$ ). At the end of the reaction, the reactor was cooled down to RT and the solution was filtered. Then, the reaction mixture was diluted five times and then analyzed with an Agilent Infinity 1260 liquid chromatograph equipped with an Aminex HPX-87H $300 \mathrm{~mm} \times 7.8 \mathrm{~mm}$ column $\left(0.005 \mathrm{M} \mathrm{H}_{2} \mathrm{SO}_{4}\right.$ solution as mobile phase) and a DAD. Compound quantifications were performed from the peak areas after calibration using commercially available samples. Recycling tests have been performed by reusing the recovered membrane without any further cleaning procedure. 


\section{Results and Discussion}

The preparation of monometallic $\mathrm{Au}$ and bimetallic $\mathrm{Au} / \mathrm{Pd}$ (molar ration 6/1) was optimized elsewhere [24] and led to the formation of small nanoparticles, having mean nanoparticle diameter of 4 and $4.5 \mathrm{~nm}$ for Au and AuPd NPs, respectively (revealed by XRD analysis and TEM-Table S4). Their impregnation on $\mathrm{TiO}_{2}$, with a metal lading of $1.5 \%$, leads to slight mean particle size increase (Figures S3 and S4).

\subsection{PAN-Based Catalytic Membranes}

\subsubsection{Characterization}

The different types of NPs supported onto $\mathrm{TiO}_{2}$ were incorporated into PAN electrospun membranes, as described in detail in the Supporting Information, and the resulting morphology was observed by SEM (Figure 1) and TEM (Figure 2).

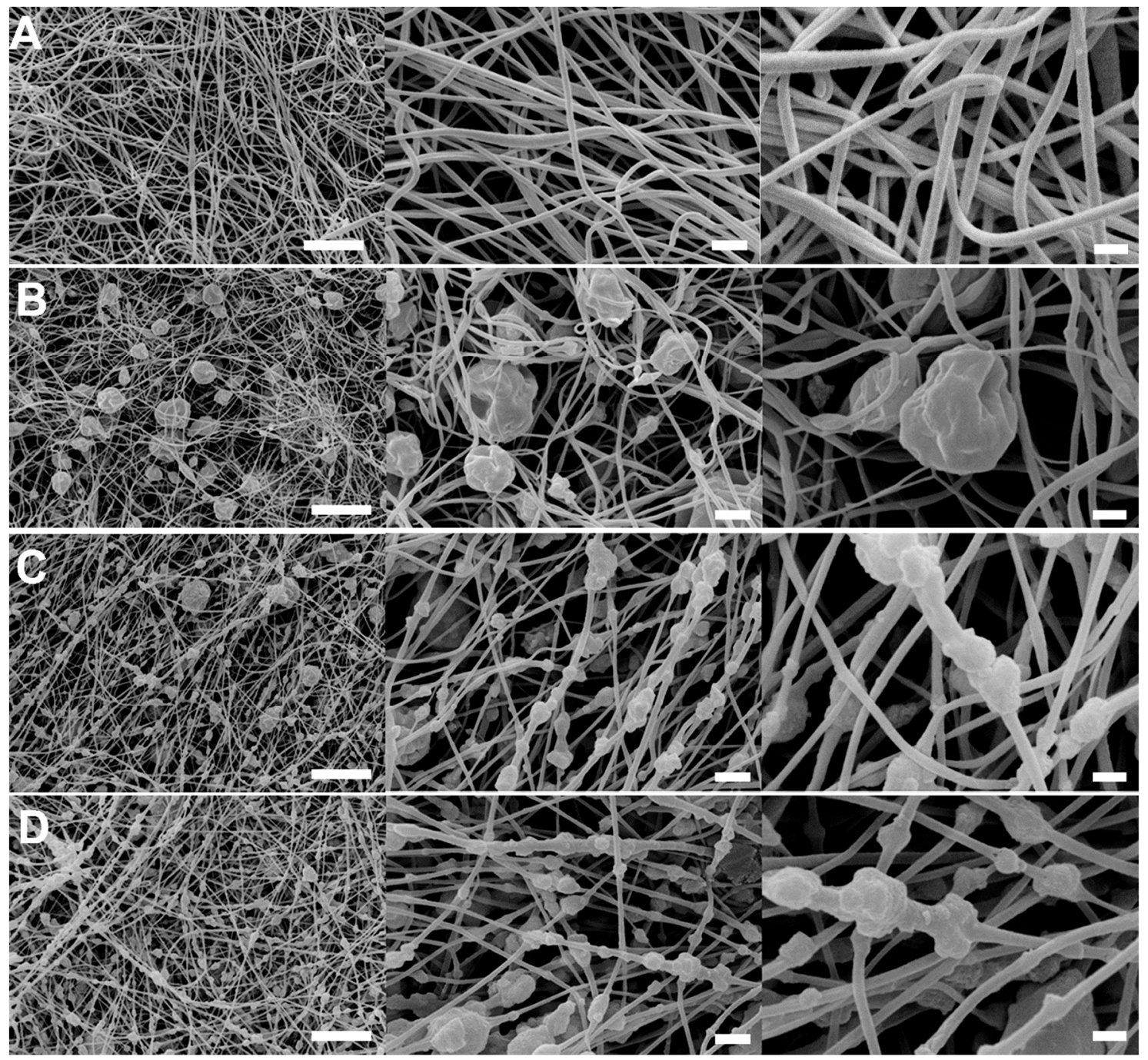

Figure 1. SEM images acquired at different magnifications of: (A) $\mathrm{PAN}$; (B) $\mathrm{PAN}+\mathrm{TiO}_{2}$; (C) $\mathrm{PAN}+$ $\mathrm{Au} / \mathrm{TiO}_{2}$ and (D) PAN $+\mathrm{AuPd} / \mathrm{TiO}_{2}$. Scale bars: $10 \mu \mathrm{m}$ (first column); $2 \mu \mathrm{m}$ (second column) and $1 \mu \mathrm{m}$ (third column). 


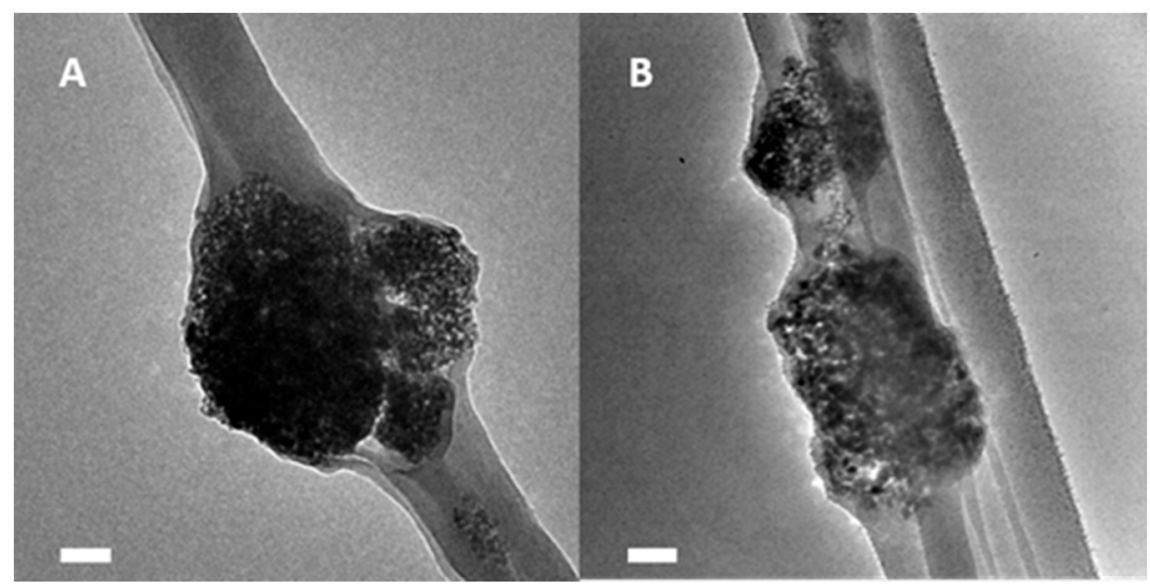

Figure 2. TEM analysis of $\mathrm{PAN}-\mathrm{Au} / \mathrm{TiO}_{2}$ and $\mathrm{PAN}-\mathrm{AuPd} / \mathrm{TiO}_{2}$ samples (A,B, respectively). Scale bars: $100 \mathrm{~nm}$.

For all types of PAN-based membranes the continuous fibers have diameters in the range 200-300 nm, similarly, to unloaded PAN membrane (Figure 1A). In $\mathrm{PAN}+\mathrm{TiO}_{2}$ (Figure 1B) the $\mathrm{TiO}_{2} \mathrm{NPs}_{\text {are }}$ round-shaped, with a rough and corrugated surface and with a broad distribution of dimensions. The smallest particles (in the range of $0.5-1 \mu \mathrm{m}$ ) are clearly incorporated along the fibers while the biggest ones (up to $5 \mu \mathrm{m}$ in diameter) are entrapped between the pores generated by the non-woven structure. In both $\mathrm{PAN}+\mathrm{Au} / \mathrm{TiO}_{2}$ and $\mathrm{PAN}+\mathrm{AuPd} / \mathrm{TiO}_{2}$ samples, the agglomerates are randomly distributed along fiber axis, mostly confined inside the PAN fibers. The particles are small (diameter 0.1-1 $\mu \mathrm{m}$ ) though being bigger than fiber diameter, thus generating a "pearl necklace" morphology. The fact that large aggregates are entrapped in the pore of $\mathrm{PAN}+\mathrm{TiO}_{2}$ while small particles are mostly incorporated in the fibers of $\mathrm{PAN}+\mathrm{Au} / \mathrm{TiO}_{2}$ and $\mathrm{PAN}+\mathrm{AuPd} / \mathrm{TiO}_{2}$ can be ascribable to the original different particle dimensions (Table S4).

TEM inspection (Figure 2) indicates the successful incorporation of $\mathrm{Au} / \mathrm{TiO}_{2}$ and $\mathrm{AuPd} / \mathrm{TiO}$ in PAN fibers and reveals that the particles observed in SEM images are aggregates of $\mathrm{TiO}_{2}$.

TGA analysis (Figure S5) confirms the organic/inorganic composition of electrospun membranes. PAN membrane shows a constant weight up to $250{ }^{\circ} \mathrm{C}$ (apart from a modest weight loss of $1 \%$ at low temperature ascribable to residual DMF evaporation, see inset), followed by a sharp weight loss of about $35 \%$ and a slower second weight loss starting from about $500{ }^{\circ} \mathrm{C}$, with a negligible weight residue at $700{ }^{\circ} \mathrm{C}$, in line with previous results [48,49]. PAN membranes loaded with supported NPs show the same degradation pattern, with weight losses proportional to the PAN content, while the residual weight at $700{ }^{\circ} \mathrm{C}$ corresponds to the inorganic phase not subjected to thermal degradation and was in the range $61 \%-62 \%$ for all membranes, as a proof of process reproducibility.

\subsubsection{Catalytic Tests}

Membranes were tested in the liquid phase oxidation of HMF. This molecule has two groups that can be oxidized: the alcoholic and the aldehydic group. The complete or partial oxidation of one or both groups may lead to the formation of different products (Scheme 1). The reaction on Au-based catalysts has been generally described in two steps: (i) the oxidation of aldehydic group to 5-hydroxymethyl-2-furancarboxylic acid (HMFCA) and (ii) the oxidation of alcoholic group-through the formation of 5-formyl-2-furancarboxylic acid (FFCA)—-to 2,5-furandicarboxylic acid (FDCA). 2,5-diformylfuran (DFF) was not generally observed in the course of the reaction with gold-base catalysts. Our study (Table 1) indicated that the plain supporting phases (either PAN or PAN $+\mathrm{TiO}_{2}$ ) were inactive in the oxidation (entry 1 and 2), while forming very small amounts of HMFCA and by-products derived from HMF degradation favored by the high $\mathrm{pH}$, in agreement with previous studies [22]. On the other hand, when Au-decorated $\mathrm{TiO}_{2}$ was inserted in the membrane network, the resulting materials display a certain activity (entry 3), which was far lower if compared to the powder 
catalyst (entry 5). This could be attributed to the fewer active sites exposed in the membrane respect to the overall active sites of the powder. The use of the bimetallic system induced a significant increase of the catalytic performance of the membrane: HMF conversion increased from $69 \%$ to $94 \%$, and a small amount of FDCA ( $2 \%$ ) was also detected with this catalyst (entry 4$)$. The improved performances of the bimetallic system compared to the Au monometallic system is correlated to the cooperative effect of the two metals in the alloyed system, as demonstrated in previous papers [24,50]. However, the catalytic activity of the AuPd-containing membrane was far lower than the one of the respective powder sample (entry 4 and 6, respectively), indicating that, also in this case, substrate access to the catalyst active sites is hindered by the polymer. It is indeed worth to point out that catalytic tests are carried out at $70^{\circ} \mathrm{C}$, a temperature significantly lower than the polymer glass transition $\left(\mathrm{T}_{\mathrm{g}}=108^{\circ} \mathrm{C}\right)$, and the polymeric phase might thus represent a diffusion barrier which is even harder to overcome in the glassy state. In order to overcome this problem, the PAN $+\mathrm{AuPd} / \mathrm{TiO}_{2}$ membrane was treated at a temperature higher than the PAN glass transition temperature. This has been done with the aim to allow polymer chain mobility, which could lead, in turn, to an improved exposure of the active sites. Alternatively, another batch of untreated membrane, was calcined at $300^{\circ} \mathrm{C}$, with the aim to understand if the thermal induced PAN cyclisation has a positive effect on the membrane catalytic performances. Nevertheless, these tests, also performed at higher temperatures (Figures S6 and S7) were not successful in recovering a higher catalytic activity.

Table 1. Catalytic performances of PAN-derived materials. Reaction conditions: $4 \mathrm{~h}, 70{ }^{\circ} \mathrm{C}, \mathrm{O}_{2}$ pressure 10 bar, 25 mL water, HMF (0.018 M), HMF:NaOH molar ratio 1:2 and HMF:metal molar ratio 100:1.

\begin{tabular}{ccccccc}
\hline Entry & Sample & $\begin{array}{c}\text { HMF } \\
\text { Conversion } \\
\mathbf{( \% )}\end{array}$ & $\begin{array}{c}\text { HMFCA } \\
\text { Yield (\%) }\end{array}$ & $\begin{array}{c}\text { FFCA Yield } \\
\mathbf{( \% )}\end{array}$ & $\begin{array}{c}\text { FDCA Yield } \\
\text { (\%) }\end{array}$ & C-LOSS (\%) \\
\hline 1 & $\mathrm{PAN}$ & 39 & 3 & 1 & 0 & 35 \\
2 & $\mathrm{PAN}+\mathrm{TiO}_{2}$ & 64 & 4 & 0 & 0 & 60 \\
3 & $\mathrm{PAN}+\mathrm{Au} / \mathrm{TiO}_{2}$ & 69 & 21 & 5 & 0 & 43 \\
4 & $\mathrm{PAN}+\mathrm{AuPd} / \mathrm{TiO}_{2}$ & 94 & 65 & 24 & 2 & 3 \\
5 & $\mathrm{Au} / \mathrm{TiO}_{2}$ & 100 & 85 & 10 & 5 & 0 \\
6 & $\mathrm{AuPd} / \mathrm{TiO}_{2}$ & 100 & 30 & 10 & 60 & 0 \\
\hline
\end{tabular}

\subsection{Nylon-Based Membranes}

With the aim of solving the diffusion problems observed with PAN nanofibers, Nylon 6,6 (NYL) was thus selected as matrix polymer for catalytic membrane production. Indeed, Nylon 6,6 has a lower glass transition $\left(\mathrm{T}_{\mathrm{g}}=50-60^{\circ} \mathrm{C}\right)$ compared to PAN coupled with a high melting temperature (Figure S8). These properties should allow good temperature stability and a slightly higher hydrophilicity with respect to PAN fibers. Stemming from previously obtained results that highlighted better performances for bimetallic systems, nanofibers were produced solely with $\mathrm{TiO}_{2}$ supported AuPd nanoparticles $\left(\mathrm{NYL}+\mathrm{AuPd} / \mathrm{TiO}_{2}\right)$. Together with the reference NPs free fibers (i.e., plain $\mathrm{NYL}$ and $\left.\mathrm{NYL}+\mathrm{TiO}_{2}\right)$, two additional catalytic membranes were also produced, one containing independently added $\mathrm{TiO}_{2}$ and unsupported AuPd NPs $\left(\mathrm{NYL}+\mathrm{AuPd}+\mathrm{TiO}_{2}\right)$ and the other containing just the unsupported AuPd NPs (NYL + AuPd). The latter two samples aimed at exploring the ability of the nanofibrous polymeric systems to stabilize the metallic nanoparticles and the role of $\mathrm{TiO}_{2}$ in the complex catalytic medium. While the procedure for adding titania supported AuPd nanoparticles $\left(\mathrm{AuPd} / \mathrm{TiO}_{2}\right)$ was similar to the previously applied method for PAN fibers (with some limitation in particle content due to high-concentration suspension stability issues during the process), addition of unsupported bimetallic NPs was possible due to the solvent system used for nylon electrospinning (formic acid/chloroform) that proved to be slightly water tolerant. Formic acid (FA) was indeed used to replace water as much as possible as NPs solvent (17 wt.\% water residual tolerated) with subsequent washing/centrifugation steps that did not alter NPs dimensions or promoted their aggregation (Figures S3 and S4). Such FA suspension was then used in a procedure similar to the one applied for plain nylon nanofibers or to 
the procedure for obtaining NYL $+\mathrm{TiO}_{2}$ nanofiber to attain NYL + AuPd and NYL $+\mathrm{AuPd}+\mathrm{TiO}_{2}$ catalytic membranes respectively.

\subsubsection{Characterization}

SEM micrographs, recorded for all the obtained nanofibrous samples (Figure 3), show thin fibers with diameters ranging in $350-80 \mathrm{~nm}$ span (Table 2).
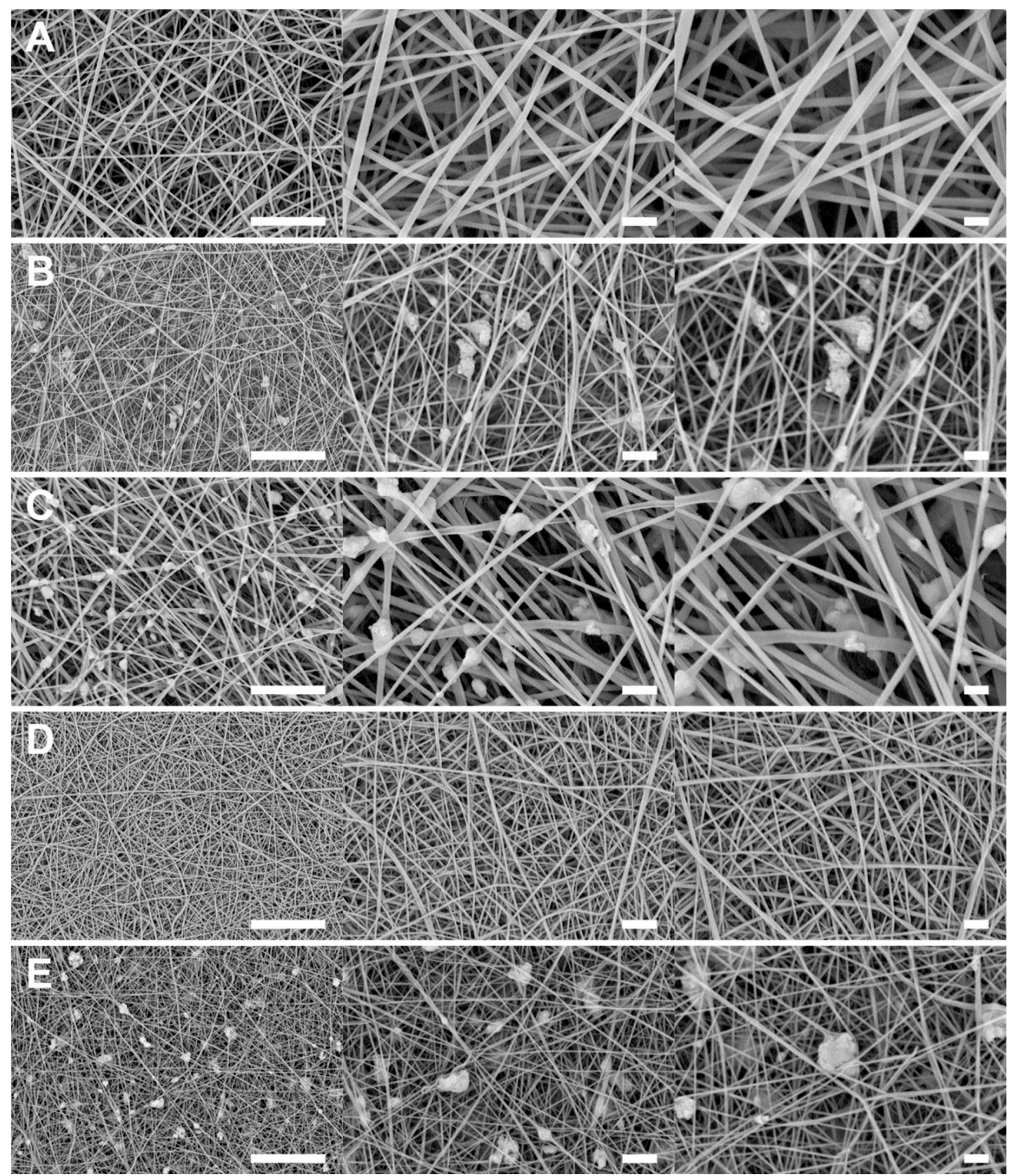

Figure 3. SEM images acquired at different magnifications of: (A) NYL; (B) $\mathrm{NYL}+\mathrm{TiO}_{2}$; (C) NYL + $\mathrm{AuPd} / \mathrm{TiO}_{2} ;(\mathbf{D}) \mathrm{NYL}+\mathrm{AuPd}$ and $(\mathrm{E}) \mathrm{NYL}+\mathrm{AuPd}+\mathrm{TiO}_{2}$. Scale bars: $10 \mu \mathrm{m}$ (first column); $2 \mu \mathrm{m}$ (second column) and $1 \mu \mathrm{m}$ (third column). 
Table 2. NYL-based membranes: fiber average diameter and specific surface area of the electrospun samples.

\begin{tabular}{ccc}
\hline Sample & Average Diameter $(\mathbf{n m})$ & Specific Surface Area $\mathbf{( m}^{\mathbf{2}} \mathbf{g}^{-\mathbf{1}} \mathbf{)}$ \\
\hline $\mathrm{NYL}$ & $320 \pm 70$ & $<10$ \\
$\mathrm{NYL}+\mathrm{TiO}_{2}$ & $130 \pm 20$ & 36 \\
$\mathrm{NYL}+\mathrm{Au} / \mathrm{PdTiO}_{2}$ & $300 \pm 80$ & 32 \\
$\mathrm{NYL}+\mathrm{AuPd}$ & $100 \pm 20$ & $<10$ \\
$\mathrm{NYL}+\mathrm{AuPd}+\mathrm{TiO}_{2}$ & $80 \pm 10$ & 36 \\
\hline
\end{tabular}

While the fibers are all thin and smooth, it was observed that inorganic component promoted fiber diameter thinning, and in particular, the presence of free unsupported AuPd NPs, decreased the average diameter around, or even below, $100 \mathrm{~nm}$. Moreover, the addition of $\mathrm{TiO}_{2}$ (both as plain titania or when NPs are supported on it) led to aggregates formation whose morphology well compared with the previously analyzed PAN based fibers. The dimension of such aggregates exceeded the fibers diameters, which by the way were way thinner than the pristine NYL counterpart, with some extroversion outside the smooth profile of the single filament. However, aggregates belonged to the fibers bulk, and were not simply leaning on the surface. The lower concentration of particles, due to the previously highlighted high-concentration suspension stability issues with the solvent system to be used for NYL fibers, provoked, in turn, minor aggregation phenomena with respect to the highly loaded PAN fibers, with no excess particle entrapment within the membrane pores. On the other side no aggregate was detected with just unsupported NPs, whose diameters were well below the fibers average size.

TGA measurements (Table S5) confirmed the trend observations with PAN fibers and the composition of the starting solution, meaning that no significant inorganic phase separation occurred during electrospinning, which might result in fibers with significant depletion of inorganic content in the fibers.

An additional important feature was also highlighted for nanofibrous membranes inorganic fillers such as titania, or NPs (either supported on titania or unsupported). Indeed, all of the "loaded fibers" are characterized by a higher $\mathrm{T}_{\mathrm{g}}$ (about $+10^{\circ} \mathrm{C}$ ) and a higher degree of crystallinity with respect to plain nylon nanofibers. The first observation accounts for a good dispersion of $\mathrm{NP}$ and $\mathrm{TiO}_{2}$ supported $\mathrm{NP}$ within the polymer, so much that the mobility of the macromolecules was hindered by the interaction with the inorganic components, with a significant increase in glass transition. As far as the crystal phase is concerned, electrospinning is well renown to discourage crystal formation, while the presence of such fillers seems to help promoting crystallization during spinning, acting as nucleants [51]. This observation, while possibly not relevant for the mere catalytic activity, can be of paramount importance when considering the fibers mechanical properties, which are strongly influenced by their crystallinity, and is an important factor when dealing with membranes that should be able to withstand continuous flow conditions.

\subsubsection{Catalytic Tests}

The screening of the catalytic performances demonstrated the inability of the bare electrospun NYL membrane to catalyze the reaction in the studied conditions (Table 3, entry 1). Indeed, in this blank experiment, in the absence of the metallic active phase, more than $90 \%$ of the fed HMF was converted into degradation products and no oxidation occurred. The addition to the membrane of $\mathrm{TiO}_{2}$-supported AuPd NPs made the membrane active in the formation of HMFCA and FFCA (Table 3, entry 2) but still low production of FDCA was evidenced. 
Table 3. Catalytic performances of NYL-derived materials. Reaction conditions: $4 \mathrm{~h}, 70{ }^{\circ} \mathrm{C}, \mathrm{O}_{2}$ pressure 10 bar, 25 mL water, HMF (0.018 M), HMF:NaOH molar ratio 1:2 and HMF:metal molar ratio 100:1.

\begin{tabular}{ccccccc}
\hline Entry & Sample & $\begin{array}{c}\text { HMF } \\
\text { Conversion } \\
\mathbf{( \% )}\end{array}$ & $\begin{array}{c}\text { HMFCA } \\
\text { Yield (\%) }\end{array}$ & $\begin{array}{c}\text { FFCA Yield } \\
\mathbf{( \% )}\end{array}$ & $\begin{array}{c}\text { FDCA Yield } \\
\mathbf{( \% )}\end{array}$ & C-LOSS \\
\hline 1 & $\mathrm{NYL}$ & 100 & 3 & 0 & 0 & 97 \\
2 & $\mathrm{NYL}+\mathrm{AuPd} / \mathrm{TiO}_{2}$ & 100 & 51 & 28 & 6 & 15 \\
3 & $\mathrm{NYL}+\mathrm{AuPd}$ & 100 & 45 & 32 & 4 & 19 \\
4 & $\mathrm{NYL}+\mathrm{TiO}_{2}+\mathrm{AuPd}$ & 100 & 50 & 28 & 14 & 8 \\
\hline
\end{tabular}

Contrarily to what was observed using PAN-based fibers, using NYL material, a strong effect of reaction temperature was observed on FDCA formation, with yield increasing from $6 \%$ up to $27 \%$ (Figure S9). Nylon, having lower glass transition temperature and higher hydrophilicity, seems to lead to lower diffusion issues.

To further increase the performance of the membrane, different materials were synthetized inserting pristine AuPd NPs colloids in the mixture to be electrospun. In particular, two different membranes have been prepared by (i) electrospinning of a suspension containing AuPd NPs colloids and nylon (NYL + AuPd sample) and (ii) electrospinning a suspension containing bare $\mathrm{TiO}_{2}$, unsupported $\mathrm{AuPd}$ $\mathrm{NPs}$ and nylon ( $\mathrm{NYL}+\mathrm{TiO}_{2}+\mathrm{AuPd}$ sample). For both samples, after $4 \mathrm{~h}$ reaction time, $\mathrm{HMF}$ conversion was complete but considerable differences were seen among catalysts in term of product selectivity. In particular, the selectivity to FDCA increased significantly for $\mathrm{TiO}_{2}$-containing sample. This feature could be ascribed to the effect of the increase of specific surface area obtained by introducing $\mathrm{TiO}_{2}$ in the membrane (Table 3).

To further demonstrate the higher suitability of such synthetic protocol, two tests at higher reaction temperature ( 90 and $110{ }^{\circ} \mathrm{C}$, Figure 4) were performed. These tests proved that temperature has a strong positive effect on FDCA yield, since it rose from $14 \%$ to $67 \%$ by increasing reaction temperature.

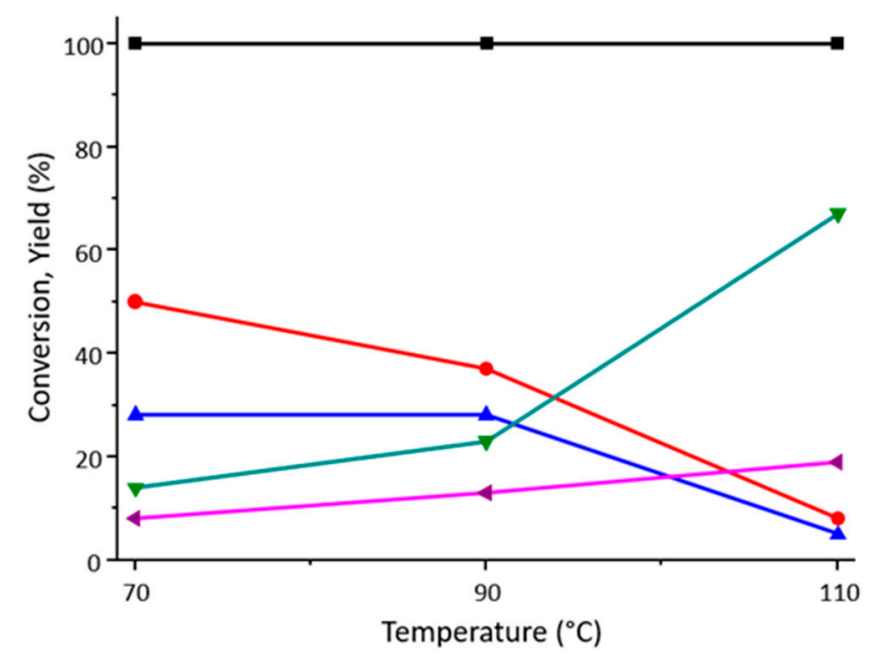

Figure 4. Reaction temperature effect on the catalytic performance of $\mathrm{NYL}+\mathrm{TiO}_{2}+\mathrm{AuPd}$ sample. Operative conditions: $4 \mathrm{~h}, \mathrm{O}_{2}$ pressure 10 bar, $25 \mathrm{~mL}$ water, $\mathrm{HMF}$ concentration $0.018 \mathrm{M}, \mathrm{HMF}: \mathrm{NaOH}$ molar ratio 1:2, HMF:(Au + Pd) molar ratio 100:1. Legend: a HMF Conversion, • HMFCA yield, $\boldsymbol{\Delta}$ FFCA yield, $\nabla$ FDCA yield, 4 C-LOSS.

In order to evaluate the $\mathrm{NYL}+\mathrm{TiO}_{2}+\mathrm{AuPd}$ membrane stability, reusability tests have been performed at $90{ }^{\circ} \mathrm{C}$ (Figure 5). Unexpectedly, $\mathrm{NYL}+\mathrm{TiO}_{2}+\mathrm{AuPd}$ catalytic membrane showed a significant increase in activity after the first catalytic test, with FDCA yield rising from $19 \%$ to $34 \%$. 


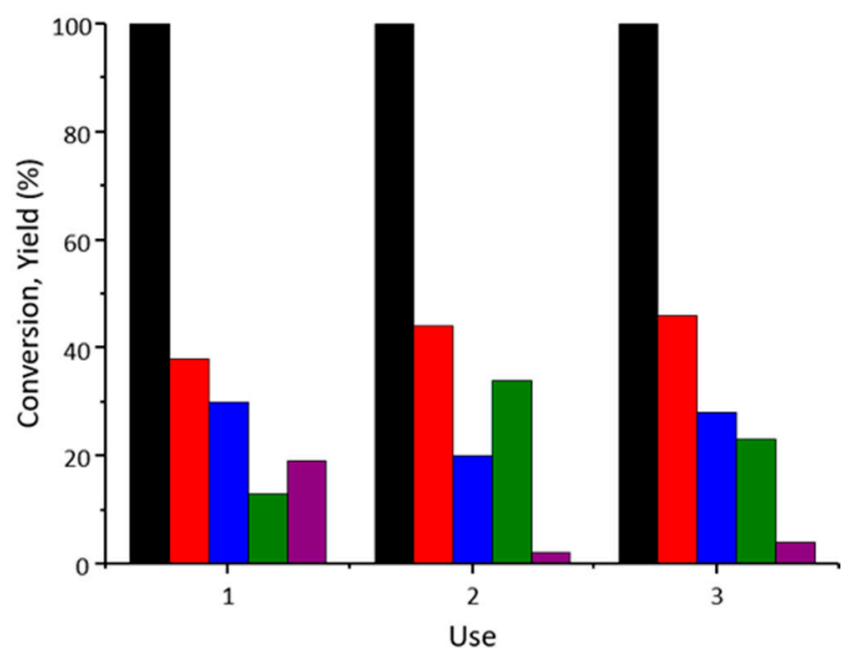

Figure 5. Reusability tests performed over $\mathrm{NYL}+\mathrm{TiO}_{2}+\mathrm{AuPd}$ composite membranes. Operative conditions: $4 \mathrm{~h}$, temperature $90{ }^{\circ} \mathrm{C}, \mathrm{O}_{2}$ pressure 10 bar, $25 \mathrm{~mL}$ water, $\mathrm{HMF}$ concentration $18 \mathrm{mM}$, HMF:NaOH molar ratio 1:2, HMF:(Au + Pd) molar ratio 100:1. Legend: — HMF Conversion, — HMFCA yield, $\square$ FFCA yield, $\square$ FDCA yield, $\square$ C-LOSS.

Since metal leaching during the reaction was excluded by chemical analysis (XRF analysis revealed that no Pd, Au of Ti species were dissolved in the reaction mixture), this initial activation effect could be attributed to a modification of the interaction between the active phase and the polymer during the reactivity experiment in water. Indeed, it is possible to hypothesize that catalytic active sites, which are hindered in the original membrane network, are made accessible by the use of the membrane in the reaction conditions, probably due to thermal induced movement of polymer chains during the reaction, which could occur because of the fact that membrane operates in temperature conditions $\left(90^{\circ} \mathrm{C}\right)$ higher than its glass transition temperature $\left(50^{\circ} \mathrm{C}\right)$. In this frame, SEM micrographs of fresh and materials used at $90^{\circ} \mathrm{C}$ and $110^{\circ} \mathrm{C}$ (Figure 6) strengthened this hypothesis. Indeed, while some fiber shrinking was observed in the pictures, no significant changes in fibers morphology were observed. Moreover, the inorganic content, as evaluated by TGA, stayed unaffected even after catalytic tests, confirming that no leaching of $\mathrm{TiO}_{2}$ or metal nanoparticles occurred during the reaction.

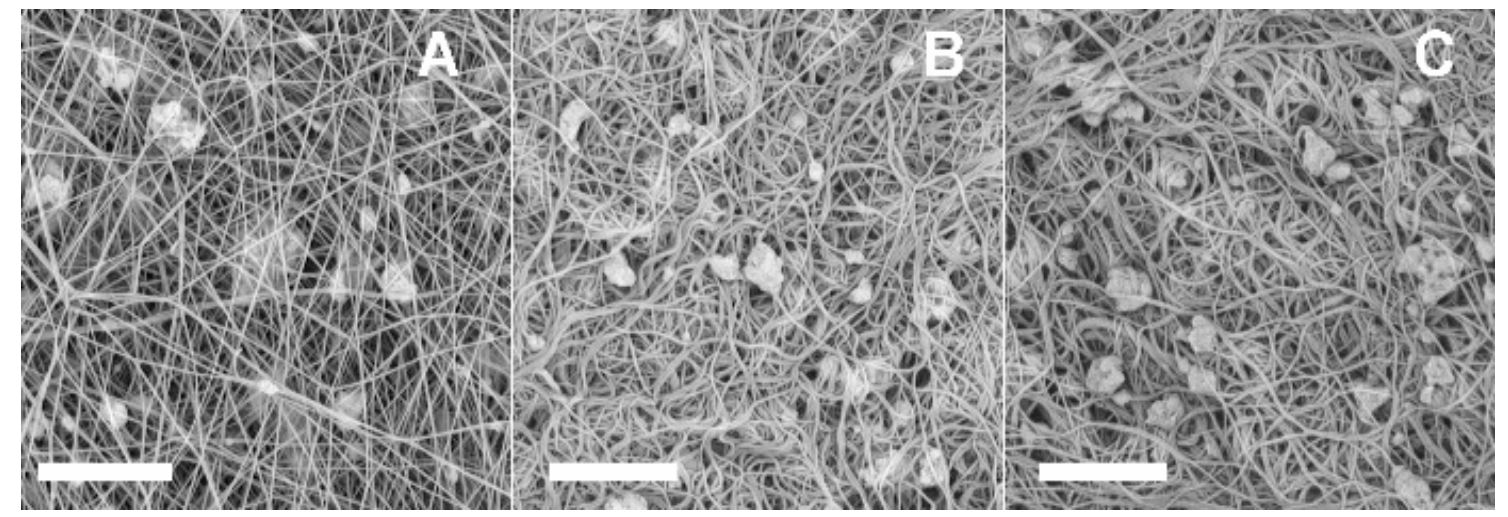

Figure 6. SEM micrographs of (A) $\mathrm{NYL}+\mathrm{AuPd}+\mathrm{TiO}_{2} ;(\mathbf{B}) \mathrm{NYL}+\mathrm{AuPd}+\mathrm{TiO}_{2}$ after reaction at $90{ }^{\circ} \mathrm{C}$ and $(\mathrm{C}) \mathrm{NYL}+\mathrm{AuPd}+\mathrm{TiO}_{2}$ after reaction at $110{ }^{\circ} \mathrm{C}$; scale bar: $5 \mu \mathrm{m}$.

Preliminary analysis using the Attenuated Total Reflection coupled with Infrared Spectroscopy (ATR-FTIR) on fresh and used materials (Figure 7) showed that no furanic-compounds were present within both membranes, and no change in its chemical composition occurred during the reaction. 


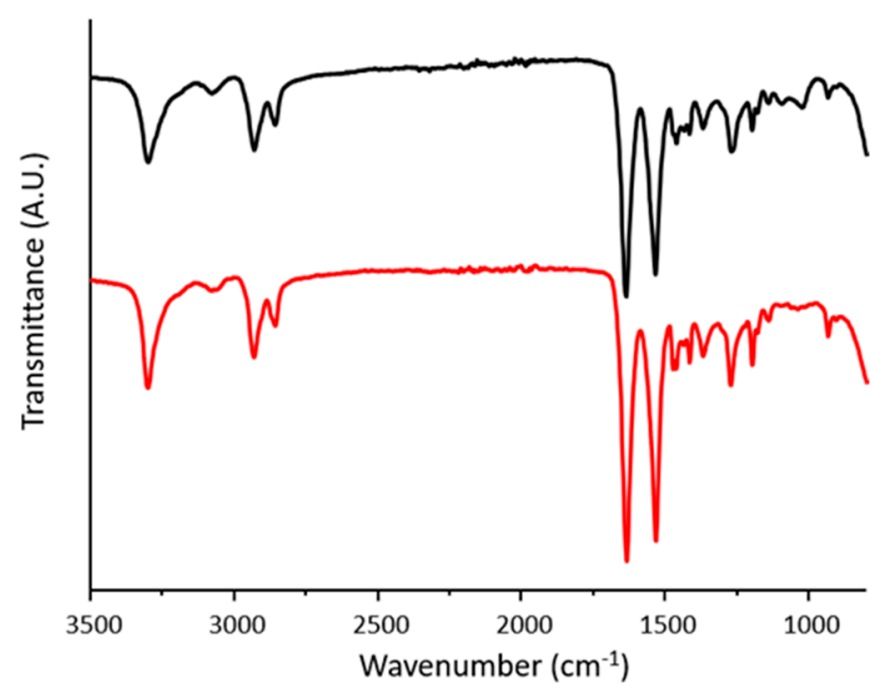

Figure 7. ATR analysis of $\mathrm{NYL}+\mathrm{TiO}_{2}+$ AuPd samples: fresh (black, up) and used (red, bottom).

\section{Conclusions}

This work demonstrated that AuPd-based nanosystems could be efficiently and quantitatively incorporated in a polymeric fibrous network via electrospinning. The resulting membranes possessed significant activity, which was strongly correlated to: (i) the chemical nature of the used polymeric matrix and (ii) the method of active-phase introduction. In particular, glass transition temperature lower than reaction temperature and high hydrophilicity positively affected membrane activity. As far as the introduction of the active phase is concerned, the addition of unsupported $\mathrm{NPs}$ and $\mathrm{TiO}_{2}$ led to the production of the most active membrane. All electrospun materials showed high catalytic and structural stability and no leaching of active phase was observed during HMF oxidation in water. In conclusion, this work helped to gain fundamental knowledge on the features that play key roles in the utilization of heterogeneous catalysts supporting membranes for biomass oxidation in water, suggesting that current strategy could be a viable way for the future development of continuous processes based on this technology.

Supplementary Materials: The following are available online at http://www.mdpi.com/2227-9717/8/1/45/s1, Figure S1: DLS analyses of NPs suspensions; Figure S2: XRD analyses of dried NPs suspensions; Figure S3: Representative TEM images of $\mathrm{Au} / \mathrm{TiO}_{2}$ supported on $\mathrm{TiO}_{2}$ and their size distribution histograms; Figure S4: Representative TEM images of $\mathrm{AuPd} / \mathrm{TiO}_{2}$ supported on $\mathrm{TiO}_{2}$ and their size distribution histograms; Figure S5: TGA analyses of PAN-based membranes; Figure S6: Effect of thermal treatments on PAN + AuPd/TiO 2 membranes catalytic activity; Figure S7: Reaction temperature effect on the catalytic performance of $\mathrm{PAN}+\mathrm{AuPd} / \mathrm{TiO} \mathrm{I}_{2}$ sample; Figure S8: DSC analyses of PAN and Nylon; Figure S9: Effect of reaction temperature on NYL $+\mathrm{AuPd} / \mathrm{TiO}_{2}$ membranes catalytic activity; Table S1: Amounts of polymer and inorganic fraction used to prepare the suspension in DMF and electrospinning processing conditions; Table S2: Amounts of polymer and inorganic fraction used to prepare $\mathrm{FA} / \mathrm{CHCl}_{3}$ suspensions; Table S3: Electrospinning processing conditions and average diameter obtained; Table S4: Characteristic of prepared catalysts and average diameters of metallic dimension estimated from XRD and TEM analysis; Table S5: Thermal characterization results for Nyl based nanofibers.

Author Contributions: D.B., L.M., E.M., and C.G. designed the different experiments and supported the interpretation of catalytic tests and material characterization; F.F. and C.S. synthesized the catalysts and carried out catalytic evaluation and characterization of materials; L.G., C.G., M.L.F., A.Z., and S.A. were involved in the writing and editing the manuscript. All authors have read and agreed to the published version of the manuscript.

Funding: This work was funded by SINCHEM Joint Doctorate Program-Erasmus Mundus Action (framework agreement $\mathrm{N}^{\circ}$ 2013-0037).

Acknowledgments: The Italian Ministry of University and Research (MIUR) is acknowledged.

Conflicts of Interest: The authors declare no conflict of interest. 


\section{References}

1. John, G.; Nagarajan, S.; Vemula, P.K.; Silverman, J.R.; Pillai, C.K.S. Natural monomers: A mine for functional and sustainable materials-Occurrence, chemical modification and polymerization. Prog. Polym. Sci. 2019, 92, 158-209. [CrossRef]

2. Ragauskas, A.J.; Williams, C.K.; Davison, B.H.; Britovsek, G.; Cairney, J.; Eckert, C.A.; Frederick, W.J.; Hallett, J.P.; Leak, D.J.; Liotta, C.L.; et al. The Path Forward for Biofuels and Biomaterials. Science 2006, 311, 484-489. [CrossRef] [PubMed]

3. Chen, G.-Q.; Patel, M.K. Plastics Derived from Biological Sources: Present and Future: A Technical and Environmental Review. Chem. Rev. 2012, 112, 2082-2099. [CrossRef] [PubMed]

4. Gandini, A. Monomers and Macromonomers from Renewable Resources. In Biocatalysis in Polymer Chemistry; John Wiley \& Sons Ltd.: Hoboken, NJ, USA, 2010; pp. 1-33. ISBN 978-3-527-63253-4.

5. Delidovich, I.; Hausoul, P.J.C.; Deng, L.; Pfützenreuter, R.; Rose, M.; Palkovits, R. Alternative Monomers Based on Lignocellulose and Their Use for Polymer Production. Chem. Rev. 2016, 116, 1540-1599. [CrossRef] [PubMed]

6. Gandini, A.; Lacerda, T.M.; Carvalho, A.J.F.; Trovatti, E. Progress of Polymers from Renewable Resources: Furans, Vegetable Oils, and Polysaccharides. Chem. Rev. 2016, 116, 1637-1669. [CrossRef]

7. Portillo Perez, G.; Mukherjee, A.; Dumont, M.-J. Insights into HMF catalysis. J. Ind. Eng. Chem. 2019, 70, 1-34. [CrossRef]

8. Li, X.; Xu, R.; Yang, J.; Nie, S.; Liu, D.; Liu, Y.; Si, C. Production of 5-hydroxymethylfurfural and levulinic acid from lignocellulosic biomass and catalytic upgradation. Ind. Crop. Prod. 2019, 130, 184-197. [CrossRef]

9. Agarwal, B.; Kailasam, K.; Sangwan, R.S.; Elumalai, S. Traversing the history of solid catalysts for heterogeneous synthesis of 5-hydroxymethylfurfural from carbohydrate sugars: A review. Renew. Sustain. Energy Rev. 2018, 82, 2408-2425. [CrossRef]

10. Zhang, D.; Dumont, M.-J. Advances in polymer precursors and bio-based polymers synthesized from 5-hydroxymethylfurfural. J. Polym. Sci. Part A Polym. Chem. 2017, 55, 1478-1492. [CrossRef]

11. Hu, L.; Lin, L.; Wu, Z.; Zhou, S.; Liu, S. Recent advances in catalytic transformation of biomass-derived 5-hydroxymethylfurfural into the innovative fuels and chemicals. Renew. Sustain. Energy Rev. 2017, 74, 230-257. [CrossRef]

12. Kucherov, F.A.; Romashov, L.V.; Galkin, K.I.; Ananikov, V.P. Chemical Transformations of Biomass-Derived C6-Furanic Platform Chemicals for Sustainable Energy Research, Materials Science, and Synthetic Building Blocks. ACS Sustain. Chem. Eng. 2018, 6, 8064-8092. [CrossRef]

13. Xia, H.; Xu, S.; Hu, H.; An, J.; Li, C. Efficient conversion of 5-hydroxymethylfurfural to high-value chemicals by chemo- and bio-catalysis. RSC Adv. 2018, 8, 30875-30886. [CrossRef]

14. Werpy, T.; Petersen, G. Top Value Added Chemicals from Biomass: Volume I-Results of Screening for Potential Candidates from Sugars and Synthesis Gas; National Renewable Energy Lab.: Golden, CO, USA, 2004.

15. Papageorgiou, G.Z.; Papageorgiou, D.G.; Terzopoulou, Z.; Bikiaris, D.N. Production of bio-based 2,5-furan dicarboxylate polyesters: Recent progress and critical aspects in their synthesis and thermal properties. Eur. Polym. J. 2016, 83, 202-229. [CrossRef]

16. Gandini, A.; Silvestre, A.J.D.; Neto, C.P.; Sousa, A.F.; Gomes, M. The furan counterpart of poly (ethylene terephthalate): An alternative material based on renewable resources. J. Polym. Sci. Part A Polym. Chem. 2009, 47, 295-298. [CrossRef]

17. Eerhart, A.J.J.E.; Faaij, A.P.C.; Patel, M.K. Replacing fossil based PET with biobased PEF; process analysis, energy and GHG balance. Energy Environ. Sci. 2012, 5, 6407-6422. [CrossRef]

18. Partenheimer, W.; Grushin, V.V. Synthesis of 2,5-Diformylfuran and Furan-2,5-Dicarboxylic Acid by Catalytic Air-Oxidation of 5-Hydroxymethylfurfural. Unexpectedly Selective Aerobic Oxidation of Benzyl Alcohol to Benzaldehyde with Metal=Bromide Catalysts. Adv. Synth. Catal. 2001, 343, 102-111. [CrossRef]

19. Singh, S.K. Heterogeneous Bimetallic Catalysts for Upgrading Biomass-Derived Furans. Asian J. Org. Chem. 2018, 7, 1901-1923. [CrossRef]

20. Cattaneo, S.; Stucchi, M.; Villa, A.; Prati, L. Gold Catalysts for the Selective Oxidation of Biomass-Derived Products. ChemCatChem 2019, 11, 309-323. [CrossRef]

21. Ventura, M.; Dibenedetto, A.; Aresta, M. Heterogeneous catalysts for the selective aerobic oxidation of 5-hydroxymethylfurfural to added value products in water. Inorg. Chim. Acta 2018, 470, 11-21. [CrossRef] 
22. Pasini, T.; Piccinini, M.; Blosi, M.; Bonelli, R.; Albonetti, S.; Dimitratos, N.; Lopez-Sanchez, J.A.; Sankar, M.; $\mathrm{He}$, Q.; Kiely, C.J.; et al. Selective oxidation of 5-hydroxymethyl-2-furfural using supported gold-copper nanoparticles. Green Chem. 2011, 13, 2091-2099. [CrossRef]

23. Albonetti, S.; Pasini, T.; Lolli, A.; Blosi, M.; Piccinini, M.; Dimitratos, N.; Lopez-Sanchez, J.A.; Morgan, D.J.; Carley, A.F.; Hutchings, G.J.; et al. Selective oxidation of 5-hydroxymethyl-2-furfural over $\mathrm{TiO}_{2}$-supported gold-copper catalysts prepared from preformed nanoparticles: Effect of Au/Cu ratio. Catal. Today 2012, 195, 120-126. [CrossRef]

24. Lolli, A.; Albonetti, S.; Utili, L.; Amadori, R.; Ospitali, F.; Lucarelli, C.; Cavani, F. Insights into the reaction mechanism for 5-hydroxymethylfurfural oxidation to FDCA on bimetallic Pd-Au nanoparticles. Appl. Catal. A Gen. 2015, 504, 408-419. [CrossRef]

25. Megías-Sayago, C.; Lolli, A.; Bonincontro, D.; Penkova, A.; Albonetti, S.; Cavani, F.; Odriozola, J.A.; Ivanova, S. Effect of gold particles size on Au/C catalyst selectivity in HMF oxidation reaction. ChemCatChem 2019. [CrossRef]

26. Villa, A.; Schiavoni, M.; Campisi, S.; Veith, G.M.; Prati, L. Pd-modified Au on carbon as an effective and durable catalyst for the direct oxidation of HMF to 2,5-furandicarboxylic acid. ChemSusChem 2013, 6, 609-612. [CrossRef]

27. Wan, X.; Zhou, C.; Chen, J.; Deng, W.; Zhang, Q.; Yang, Y.; Wang, Y. Base-Free Aerobic Oxidation of 5-Hydroxymethyl-furfural to 2,5-Furandicarboxylic Acid in Water Catalyzed by Functionalized Carbon Nanotube-Supported Au-Pd Alloy Nanoparticles. ACS Catal. 2014, 4, 2175-2185. [CrossRef]

28. Bonincontro, D.; Lolli, A.; Villa, A.; Prati, L.; Dimitratos, N.; Veith, G.M.; Chinchilla, L.E.; Botton, G.A.; Cavani, F.; Albonetti, S. AuPd-nNiO as an effective catalyst for the base-free oxidation of HMF under mild reaction conditions. Green Chem. 2019, 21, 4090-4099. [CrossRef]

29. Gupta, N.K.; Nishimura, S.; Takagaki, A.; Ebitani, K. Hydrotalcite-supported gold-nanoparticle-catalyzed highly efficient base-free aqueous oxidation of 5-hydroxymethylfurfural into 2,5-furandicarboxylic acid under atmospheric oxygen pressure. Green Chem. 2011, 13, 824-827. [CrossRef]

30. Ferraz, C.P.; Zieliński, M.; Pietrowski, M.; Heyte, S.; Dumeignil, F.; Rossi, L.M.; Wojcieszak, R. Influence of Support Basic Sites in Green Oxidation of Biobased Substrates Using Au-Promoted Catalysts. ACS Sustain. Chem. Eng. 2018, 6, 16332-16340. [CrossRef]

31. Dessbesell, L.; Souzanchi, S.; Rao, K.T.V.; Carrillo, A.A.; Bekker, D.; Hall, K.A.; Lawrence, K.M.; Tait, C.L.J.; Xu, C. (Charles) Production of 2,5-furandicarboxylic acid (FDCA) from starch, glucose, or high-fructose corn syrup: Techno-economic analysis. Biofuels Bioprod. Biorefin. 2019, 13, 1234-1245. [CrossRef]

32. Wiles, C.; Watts, P. Continuous process technology: A tool for sustainable production. Green Chem. 2013, 16, 55-62. [CrossRef]

33. Morse, P.D.; Beingessner, R.L.; Jamison, T.F. Enhanced Reaction Efficiency in Continuous Flow. Isr. J. Chem. 2017, 57, 218-227. [CrossRef]

34. Paired Electrochemical Oxidation process for feasible industrial production of the crucial FDCA building block for the bioplastic industry | PairElOx Project | H2020 | CORDIS | European Commission. Available online: https://cordis.europa.eu/project/rcn/217556/factsheet/en (accessed on 19 November 2019).

35. Kastl, R.; Kaufmann, E.; Bodenmüller, A.; Sedelmeier, G. Process for Preparing 2,5-Furandicarboxylic Acid. assigned to SYNPHABASE AG [CH/CH]; Gueterstrasse 824133 Pratteln (CH). Patent WO2019/072920, 18 April 2019.

36. Liguori, F.; Barbaro, P.; Calisi, N. Continuous-Flow Oxidation of HMF to FDCA by Resin-Supported Platinum Catalysts in Neat Water. ChemSusChem 2019, 12, 2558-2563. [CrossRef] [PubMed]

37. Latsuzbaia, R.; Bisselink, R.; Anastasopol, A.; Van der Meer, H.; Van Heck, R.; Yagüe, M.S.; Zijlstra, M.; Roelands, M.; Crockatt, M.; Goetheer, E.; et al. Continuous electrochemical oxidation of biomass derived 5-(hydroxymethyl)furfural into 2,5-furandicarboxylic acid. J. Appl. Electrochem. 2018, 48, 611-626. [CrossRef]

38. Drioli, E.; Brunetti, A.; Profio, G.D.; Barbieri, G. Process intensification strategies and membrane engineering. Green Chem. 2012, 14, 1561-1572. [CrossRef]

39. Brunetti, A.; Zito, P.F.; Giorno, L.; Drioli, E.; Barbieri, G. Membrane reactors for low temperature applications: An overview. Chem. Eng. Process. Process. Intensif. 2018, 124, 282-307. [CrossRef]

40. Xue, J.; Wu, T.; Dai, Y.; Xia, Y. Electrospinning and Electrospun Nanofibers: Methods, Materials, and Applications. Chem. Rev. 2019, 119, 5298-5415. [CrossRef] 
41. Gualandi, C.; Celli, A.; Zucchelli, A.; Focarete, M.L. Nanohybrid Materials by Electrospinning. In Organic-Inorganic Hybrid Nanomaterials; Advances in Polymer Science; Kalia, S., Haldorai, Y., Eds.; Springer International Publishing: Cham, Switzerland, 2015; pp. 87-142. ISBN 978-3-319-13593-9.

42. Li, B.; Zhang, B.; Nie, S.; Shao, L.; Hu, L. Optimization of plasmon-induced photocatalysis in electrospun $\mathrm{Au} / \mathrm{CeO} 2$ hybrid nanofibers for selective oxidation of benzyl alcohol. J. Catal. 2017, 348, 256-264. [CrossRef]

43. Liu, Y.; Chen, H.-S.; Li, J.; Yang, P. Morphology adjustment of one dimensional CeO2 nanostructures via calcination and their composite with Au nanoparticles towards enhanced catalysis. RSC Adv. 2015, 5, 37585-37591. [CrossRef]

44. Hao, Y.; Shao, X.; Li, B.; Hu, L.; Wang, T. Mesoporous TiO2 nanofibers with controllable Au loadings for catalytic reduction of 4-nitrophenol. Mater. Sci. Semicond. Process. 2015, 40, 621-630. [CrossRef]

45. Yue, G.; Li, S.; Li, D.; Liu, J.; Wang, Y.; Zhao, Y.; Wang, N.; Cui, Z.; Zhao, Y. Coral-like Au/TiO 2 Hollow Nanofibers with Through-Holes as a High-Efficient Catalyst through Mass Transfer Enhancement. Langmuir 2019, 35, 4843-4848. [CrossRef]

46. Liu, Y.; Jiang, G.; Li, L.; Chen, H.; Huang, Q.; Jiang, T.; Du, X.; Chen, W. Preparation of Au/PAN nanofibrous membranes for catalytic reduction of 4-nitrophenol. J. Mater. Sci. 2015, 50, 8120-8127. [CrossRef]

47. Liu, Y.; Zhang, K.; Li, W.; Ma, J.; Vancso, G.J. Metal nanoparticle loading of gel-brush grafted polymer fibers in membranes for catalysis. J. Mater. Chem. A 2018, 6, 7741-7748. [CrossRef]

48. Cipriani, E.; Zanetti, M.; Bracco, P.; Brunella, V.; Luda, M.P.; Costa, L. Crosslinking and carbonization processes in PAN films and nanofibers. Polym. Degrad. Stab. 2016, 123, 178-188. [CrossRef]

49. Mathur, R.B.; Bahl, O.P.; Sivaram, P. Thermal degradation of polyacrylonitrile fibres. Curr. Sci. 1992, 62, 662-669.

50. Albonetti, S.; Lolli, A.; Morandi, V.; Migliori, A.; Lucarelli, C.; Cavani, F. Conversion of 5-hydroxymethylfurfural to 2,5-furandicarboxylic acid over Au-based catalysts: Optimization of active phase and metal-support interaction. Appl. Catal. B Environ. 2015, 163, 520-530. [CrossRef]

51. Maccaferri, E.; Mazzocchetti, L.; Benelli, T.; Zucchelli, A.; Giorgini, L. Morphology, thermal, mechanical properties and ageing of nylon 6,6/graphene nanofibers as $\mathrm{Nano}_{2}$ materials. Compos. Part B Eng. 2019, 166, 120-129. [CrossRef]

(C) 2020 by the authors. Licensee MDPI, Basel, Switzerland. This article is an open access article distributed under the terms and conditions of the Creative Commons Attribution (CC BY) license (http://creativecommons.org/licenses/by/4.0/). 